\title{
EFFECTS OF WOLLASTONITE ON THE PROPERTIES OF MEDIUM-DENSITY FIBERBOARD (MDF) MADE FROM WOOD FIBERS AND CAMEL-THORN
}

\author{
Hamid R. Taghiyari, ${ }^{1, \wedge}$, Behrooz Mohammad-Panah ${ }^{1}$, Jeffrey J. Morrell ${ }^{2}$
}

\begin{abstract}
The effects of wollastonite fibers on the physical and mechanical properties of medium-density fiberboards composed of wood fibers with up to $10 \%$ camel-thorn chips were studied. Approximately $30 \%$ of the wollastonite fibers were less than $100 \mathrm{~nm}$ while the remainder were less than $1 \mu \mathrm{m}$. Wollastonite fibers significantly improved most of the physical and mechanical properties while addition of camel-thorn produced more variable effects on panel properties. Up to $10 \%$ camel-thorn could be added to panels without negative effects. A combination of $10 \%$ camel-thorn and $5 \%$ wollastonite fibers produced panels with the best properties.
\end{abstract}

Keywords: Camel-thorn weed, minerals, nano-materials, particleboard, thermal conductivity coefficient, wollastonite, wood-composite.

\section{INTRODUCTION}

Wood is a valuable material that can be used in a variety of applications. However, natural regeneration of trees cannot satisfy the growing demand for this raw material in some parts of the world. While solid wood is generally preferred for most applications, a variety of composite panels have emerged to allow for production of larger dimension materials from a variety of lignocellulosic materials (Xing et al. 2007, Zini \& Scandola 2011, Nayeri et al. 2013). A shortage of raw materials in some regions has stimulated a search for new fiber sources for panel production. Potential natural or synthetic fibers, such as kenaf fibers, rice straw, chicken-feather, and glass fibers have been explored for these applications (Joshi et al. 2004, Juliana et al. 2012, Taghiyari et al. 2014a). These materials have differing effects on panel properties and any substitute must be thoroughly explored to ensure that it is compatible with the production process and results in a panel with acceptable material properties.

Camel-thorn (Alhagi maurorum) is a native plant of Western Europe and central Asia that has become an agricultural weed that competes for nutrients with crop plants. Camel-thorn is a spiny shrub that forms large patches by vegetative propagation by rhizomes (underground stems). While there are no estimates of the volumes available in Iran, it is considered a weed in agricultural field. However, it can be useful for preventing soil erosion in deserts and non-agricultural fields. This material might be useful as an extender or replacement for wood in composite panel products.

${ }^{1}$ Wood Science and Technology Department, Faculty of Civil Engineering, Shahid Rajaee Teacher Training University, Lavizan, Shabanloo St., Tehran, Iran.

${ }^{2}$ Department of Wood Science \& Engineering, College of Forestry, Oregon State University, Corvallis, Oregon, USA.

"Corresponding author: htaghiyari@srttu.edu

Received: 09.05.2015 Accepted: 23.11.2015 
Over the last two decades, nanotechnology has been used to improve the properties of many materials including solid wood and wood-composite panels. Examples include the use of metal nanoparticles to increase thermal conductivity, to enhance panel pressing (Khojier et al. 2010, Drelish 2013, Saber et al. 2013), the use of nano-copper or silver particles to improve resistance to microbial attack (Akhtari et al. 2013, Maresi et al. 2013, Taghiyari et al. 2014a) and the addition of nano-wollastonite to enhance fire resistance (Ozdemir and Tutus 2013, Taghiyari et al. 2013a, 2014). Nano particles appear to produce a series of unique changes in material properties not produced with larger particles of the same material (Li 2012).

Wollastonite is a calcium silicate mineral that enhances plant growth and reduces the effects of certain pathogens, including fungi (Aitken 2010). It has minimal effects on humans or wildlife, although long term exposure studies have not yet been performed (Huuskonen et al. 1983, Maxim \& McConnell 2005, Maxim et al. 2014a,b). Wollastonite has a high thermal conductivity coefficient that could accelerate the transfer of heat from hot-press plates and facilitate resin curing in the center of the mat (Taghiyari et al. 2013b, 2014b). Enhanced curing can improve the properties of wood-based panel products such as medium density fiberboard. Therefore, the present study examined the effects of the addition of wollastonite fibers (NW) to medium-density fiberboards (MDF) panels on the physical and mechanical properties of medium-density fiberboard with different NW-contents as a possible fiber extender.

\section{EXPERIMENTAL METHODS}

\section{Specimen preparation}

Defibrillated fibers composed of beech (Fagus orientalis), alder (Alnus glutinosa), maple (Acer hyrcanum), hornbeam (Carpinus betulus), and three poplar species (Populus nigra, Populus deltoides, and Populus euroamericana) wood were obtained (Sanaye Choobe Khazar Company, Iran). Camelthorn (Alhagi maurorum) was gathered from fields in a Tehran suburb. The material was air-dried, ground with a Pallmann grinder (type: PHT $120 \times 430$ ) and then with a Pallmann flaker (type: PZ8) to prepare the chips. A $100 \mathrm{~g}$ sample of camel thorn particles was taken to determine particle dimensions $(+/-0,01 \mathrm{~mm})$. The particles averaged $8,53 \mathrm{~mm}$ long by $0,98 \mathrm{~mm}$ thick and had a slenderness ratio of 8,6 . The camel thorn particles were added at rates of 5 or $10 \%(\mathrm{w} / \mathrm{w})$ to the wood fibers and thoroughly mixed prior to use.

\section{Wollastonite application}

Wollastonite (NW) (Vard Manufacturing Company of Mineral and Industrial Products, Iran) contained a mixture of $30 \%$ particles that were no more than $100 \mathrm{~nm}$ long and the remainder that were no more than $1 \mu \mathrm{m}$ in length (Table 1). Dry NW was blended with liquid urea formaldehyde (UF) resin at three different levels $(0,5$ and $10 \% \mathrm{w} / \mathrm{w} / \mathrm{NW}$ in UF resin). MDF panels contained $10 \%$ of UF with a viscosity of 200-400 cP, 47 seconds of gel time, and a density of 1,277 g/ $\mathrm{cm}^{3}$ (Sari Resin Manufacturing Company, Sari, Iran). Solid content of the UF resin was $56 \%$. 
Table 1. Composition of the Wollastonite evaluated in the study. (Taghiyari et al. 2013b, Taghiyari et al. 2013c)

\begin{tabular}{|c|c|}
\hline Component & Proportion (\%w/w) \\
\hline $\mathrm{CaO}$ & 39,77 \\
\hline $\mathrm{SiO}_{2}$ & 46,96 \\
\hline $\mathrm{Al}_{2} \mathrm{O}_{3}$ & 3,95 \\
\hline $\mathrm{Fe}_{2} \mathrm{O}_{3}$ & 2,79 \\
\hline $\mathrm{TiO}_{2}$ & 0,22 \\
\hline $\mathrm{K}_{2} \mathrm{O}$ & 0,04 \\
\hline $\mathrm{MgO}$ & 1,39 \\
\hline $\mathrm{Na}_{2} \mathrm{O}$ & 0,16 \\
\hline $\mathrm{SO}_{3}$ & 0,05 \\
\hline $\mathrm{Water}$ & 4,67 \\
\hline
\end{tabular}

\section{Panel manufacturing}

A dry process was used to produce the MDF panels. UF resin was added at a rate of $10 \%$ based on the dry weight of wood fibers. The NW/UF mixture was sprayed on the wood fibers with or without 5 or $10 \%$ camel thorn particles and thoroughly mixed in a rotating drum before hot pressing. Average moisture content at the time of pressing was $7,35 \%$. The blended fibers were manually poured into a $43 \times 43 \mathrm{~cm}$ frame to form the mat which was then pressed at $170^{\circ} \mathrm{C}$ and $16 \mathrm{~N} / \mathrm{mm}^{2}$ for 7 minutes to produce $16 \mathrm{~mm}$ thick panels with a target density of $750 \mathrm{~kg} / \mathrm{m}^{3}$. Five replicate boards were made for each treatment and the panels were conditioned at $25 \pm 2{ }^{\circ} \mathrm{C}$ and $45 \pm 3 \%$ relative humidity for two weeks after pressing. The outer $30 \mathrm{~mm}$ around each panel was cut away prior to sample preparation to remove less consolidated panel material that might not be representative of a full size panel.

\section{Panel Testing}

Specimens were cut from the panels for physical and mechanical tests according to the procedures described in ISIRI Standard 9044 PB Type 2 which is similar to procedures described in ASTM Standard D-1037 (Table 2). Each test was performed on two samples cut from each of the five panels prepared for each treatment variable.

Table 2. Dimensions of samples used for evaluating properties of MDF panels.

\begin{tabular}{|l|l|}
\hline Test & Sample Dimensions (mm) \\
\hline Center Point Loading (MOR/MOE) & $400 \times 75$ (loading span: 320$)$ \\
\hline Internal Bond Strength (IB) & $75 \times 75$ \\
\hline Thickness Swelling/Water absorption & $75 \times 75$ \\
\hline Hardness & $150 \times 75$ \\
\hline Each test procedure was performed on two samples cut from each of five panels per treatment. \\
\hline
\end{tabular}

Center point loading tests were performed on an Instron 4486 Universal Testing machine over a $320 \mathrm{~mm}$ span. The samples were loaded at a rate of $2 \mathrm{~mm}$ per minute and load/deflection data were continuously recorded. These data were used to calculate modulus of elasticity (MOE) and modulus of rupture (MOR).

Internal bond strength was determined by gluing aluminum blocks to each face of the test sample and then pulling the blocks apart. Internal bond strength (IB) was calculated as the load required to break the sample over the surface area. 
Water absorption was measured by weighing samples before and after 2 or 24 hours of soaking in distilled water. Thickness swelling was determined on the same samples by measuring thickness at pre-determined points on each sample before and after the water immersion.

Panel hardness was assessed using a 11,28 mm diameter modified Janka ball a with a projected impact area of $100 \mathrm{~mm}^{2}$. Two test specimens were bound together to produce the $32 \mathrm{~mm}$ thickness to cover the minimum thickness of $25 \mathrm{~mm}$ specified in the standard and two tests were made on each of the flat faces. The data were averaged for each panel. Loading was applied at a uniform rate of $4 \mathrm{~mm} /$ min to a penetration depth of $5,4 \mathrm{~mm}$.

\section{SEM imaging}

The distribution of wollastonite in the MDF was evaluated by sputter-coating small samples with gold-palladium and then examining these samples under a field emission scanning electron microscope at an accelerating voltage of $20 \mathrm{kV}$. Specimens were first positioned in a vacuum mini-chamber before the coating and SEM imaging were carried out. At least two samples from each wollastonite treatment were examined and four fields were observed on each specimen. The results were intended to provide a qualitative measure of wollastonite distribution.

\section{Statistical analysis}

The data were subjected to a two-way analysis of variance (ANOVA) using SAS software, version $9.2(2010)$ at a $95 \%$ level of confidence.

\section{RESULTS AND DISCUSSION}

\section{Flexural Properties}

The addition of camel thorn particles had no noticeable effect on either MOE or MOR of the resulting MDF panels $(\mathrm{P}<0,236)$ (Figures 1,2). The addition of wollastonite to wood-based panels had no effect at $5 \% \mathrm{NW}$, but produced significant improvements in MOR and MOE when $10 \% \mathrm{NW}$ was added $(\mathrm{P}<0,008)$. Similar, but less substantial improvements were noted in panels containing the wood/camel thorn mixtures. Wollastonite has the potential to improve heat transfer properties (Taghiyari et al. 2013b,c, 2014b). Enhanced heat transfer would result in more efficient resin curing that might translate into improved panel properties.

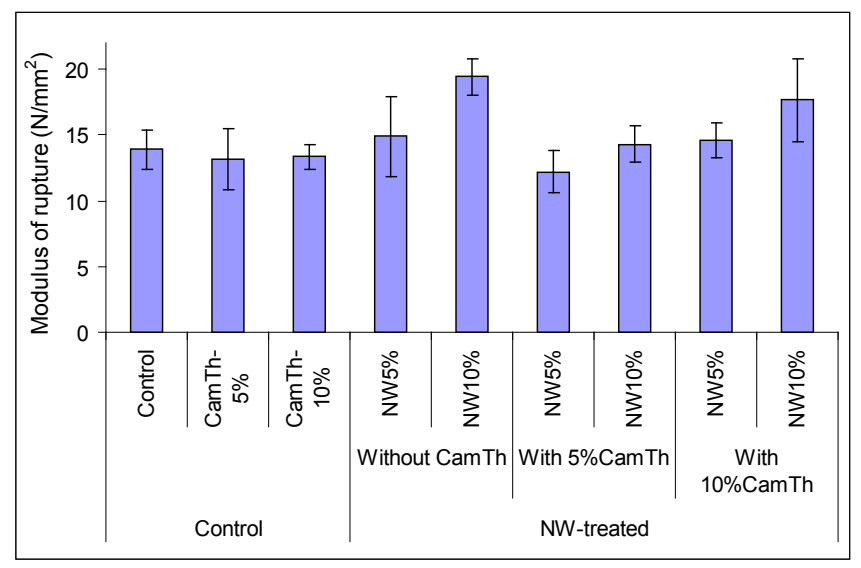

Figure 1. Effect of addition of camel thorn particles and/or wollastonite on modulus of rupture of MDF panels (values represent averages of 10 replicates per variable. Error bars represent one standard deviation) (NW=nanowollastonite; $\mathrm{CamTh}=\mathrm{Camel}$ thorn). 


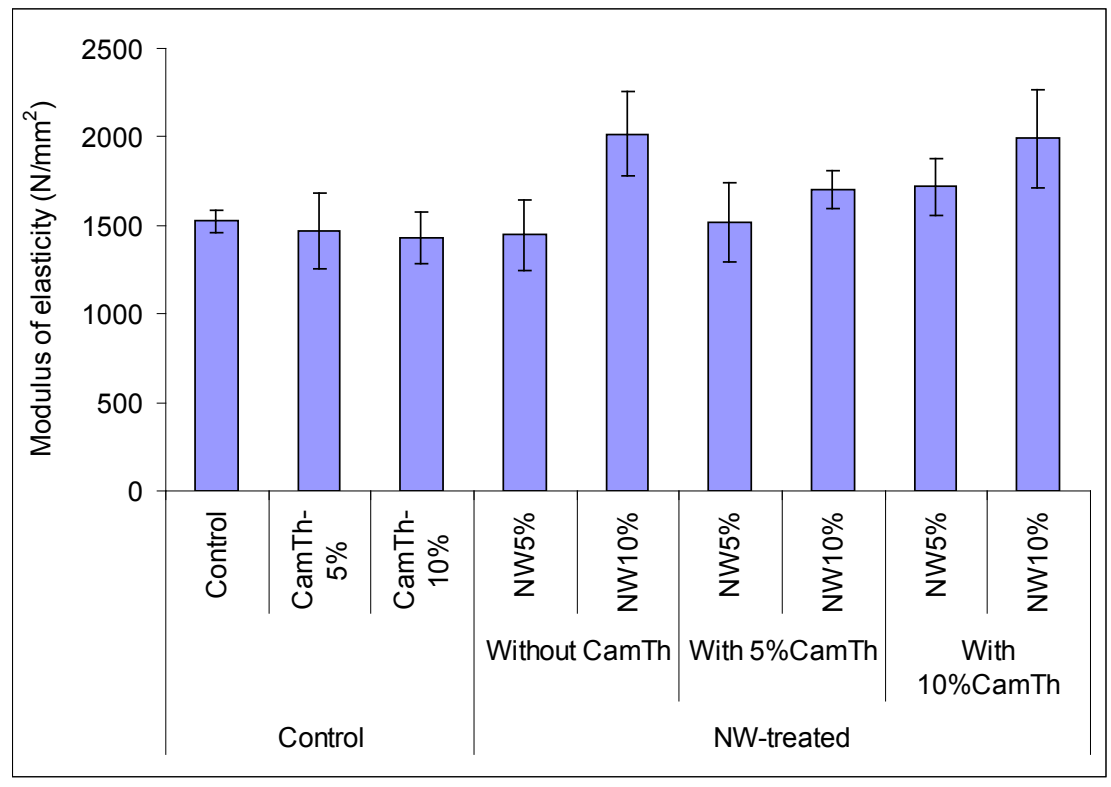

Figure 2. Effect of addition of camel thorn particles and/or wollastonite on modulus of elasticity of MDF panels (values represent averages of 10 replicates per variable. Error bars represent one standard deviation) (NW=nanowollastonite; $\mathrm{CamTh}=\mathrm{Camel}$ thorn).

\section{Water Absorption}

MDF panels are typically used in interior applications, but still need to exhibit some resistance to water absorption. The addition of camel thorn had no significant effect on water absorption after 2 or 24 hours of immersion $(\mathrm{P}<0,16)$ (Figure 3$)$. The addition of $5 \% \mathrm{NW}$ to wood MDF panels also had no noticeable effect on water absorption, but the addition of $10 \% \mathrm{NW}$ significantly reduced water uptake ( $\mathrm{P}<0,02)$. The addition of NW to panels containing $5 \%$ camel thorn particles had no effect on water uptake, while adding $10 \% \mathrm{NW}$ had a slight, though not statistically significant effect $(\mathrm{P}<0,09)$. The addition of NW to panels containing $10 \%$ camel thorn particles produced noticeable reductions in average water uptake after 2 hours of immersion, but the differences were not significant $(P<0,09)$. The effect diminished slightly after 24 hours of immersion, but the combination of NW and camel thorn did appear to improve short term moisture resistance. 


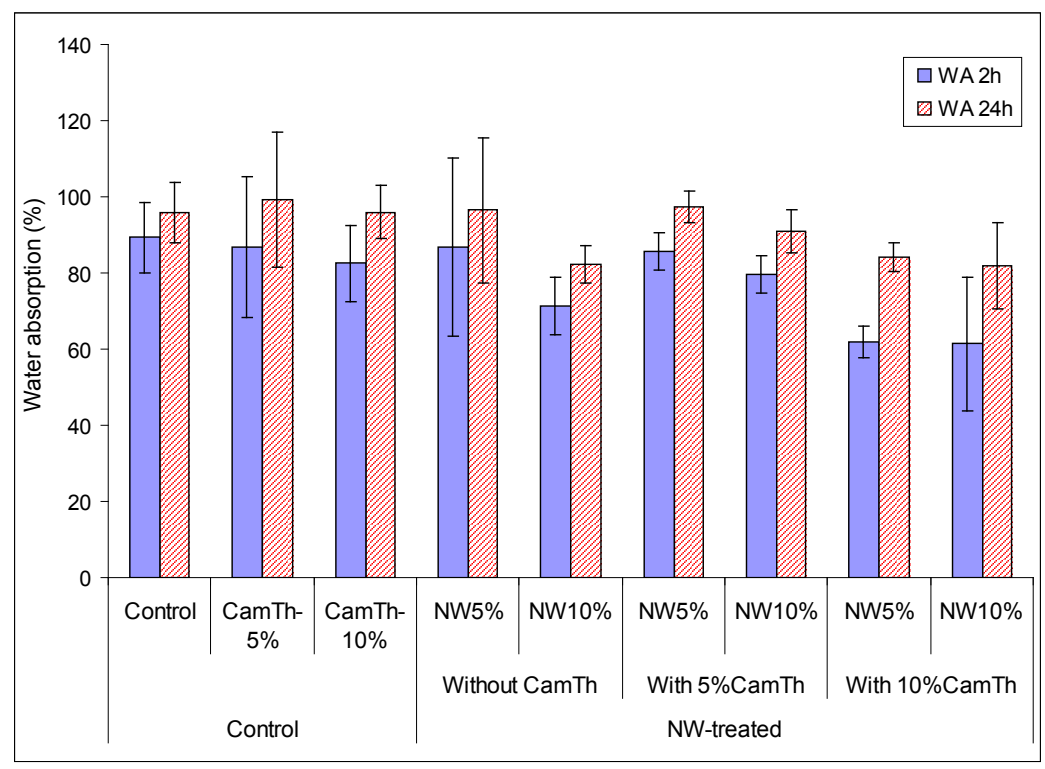

Figure 3. Effect of addition of wollastonite and/or camel thorn particles to wood based MCDF on water absorption after 2 or 24 hours of immersion (values represent averages of 10 replicates per variable. Error bars represent one standard deviation) ( $\mathrm{NW}=$ nanowollastonite; $\mathrm{CamTh}=\mathrm{Camel}$ thorn).

\section{Thickness swelling}

The addition of $5 \%$ camel thorn to wood-based MDF produced a slight increase in thickness swelling $(\mathrm{P}<0,11)$; while addition of $10 \%$ camel thorn produced a significant reduction in thickness swelling $(\mathrm{P}<0,03)$ (Figure 4). Panels with $5 \% \mathrm{NW}$ showed slight decrease in swelling $(\mathrm{P}<0,07)$ while those with $10 \%$ NW had significantly lower thickness swell values than those with wood alone $(\mathrm{P}<0,005)$. The results were surprising given the small differences found with water absorption. The potential for NW to enhance heat transfer and improve resin curing might also improve the degree to which the resin protected the fibers. NW also has a somewhat lower tendency to sorb water, although this effect would be relatively small given the low percentage of NW in the panels. NW has the potential to react with hydroxyl and methoxy groups in the lignocellulosic matrix which would reduce the hygroscopicity of the panel (Taghiyari et al. $2013 \mathrm{bc}$ ). Similar interactions have been noted between nano-clays and wood (Rangavar 2005). These reactions would also have the potential to improve flexural properties of the resulting panels. It is unclear why the presence of camel thorn particles enhanced resistance to thickness swell without producing a corresponding reduction in water absorption. 


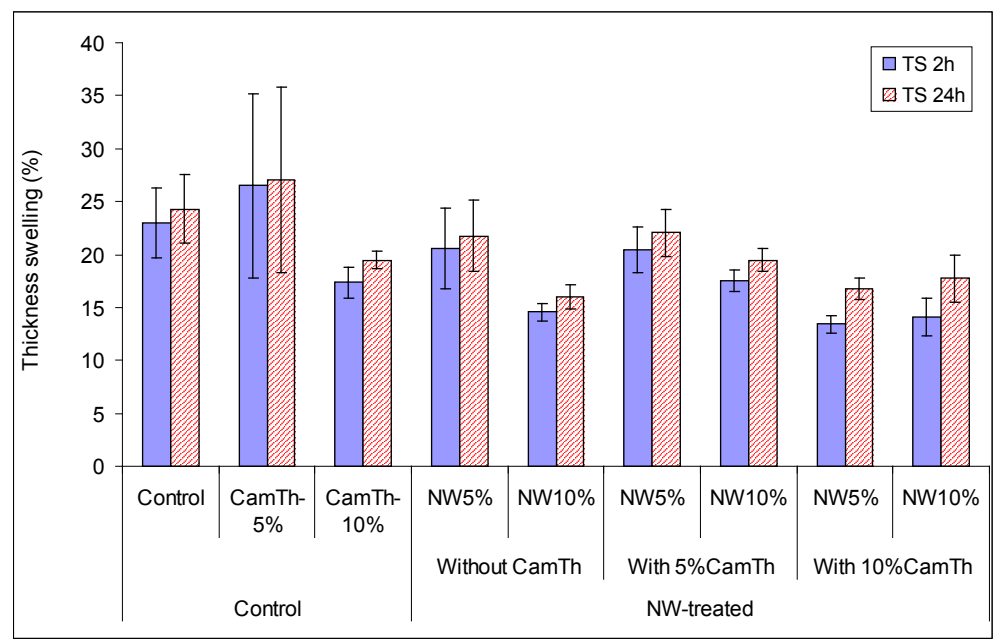

Figure 4. Effect of addition of wollastonite and/or camel thorn particles to wood based MCDF on thickness swelling after 2 or 24 hours of immersion (values represent averages of 10 replicates per variable. Error bars represent one standard deviation) ( $\mathrm{NW}=$ nanowollastonite; $\mathrm{CamTh}=\mathrm{Camel}$ thorn).

\section{Internal Bond Strength}

The addition of camel thorn had no significant effect on internal bond strength of the panels $(\mathrm{P}<$ $0,34)$ (Figure 5). This would allow camel thorn to be used as an extender without adversely affecting this property. The addition of 5 or $10 \% \mathrm{NW}$ to all wood MDF or wood MDF amended with $10 \%$ camel thorn was associated with significantly higher IB strength $(\mathrm{P}<0,048)$; but had no noticeable effect on IB of panels amended with $5 \%$ camel thorn alone. The improvement in IB values in NW-treated panels was again attributed to the increase in thermal conductivity; but it is unclear why the lower level of camel thorn did not improve properties, given the noticeable effects of NW on the non-amended panels.

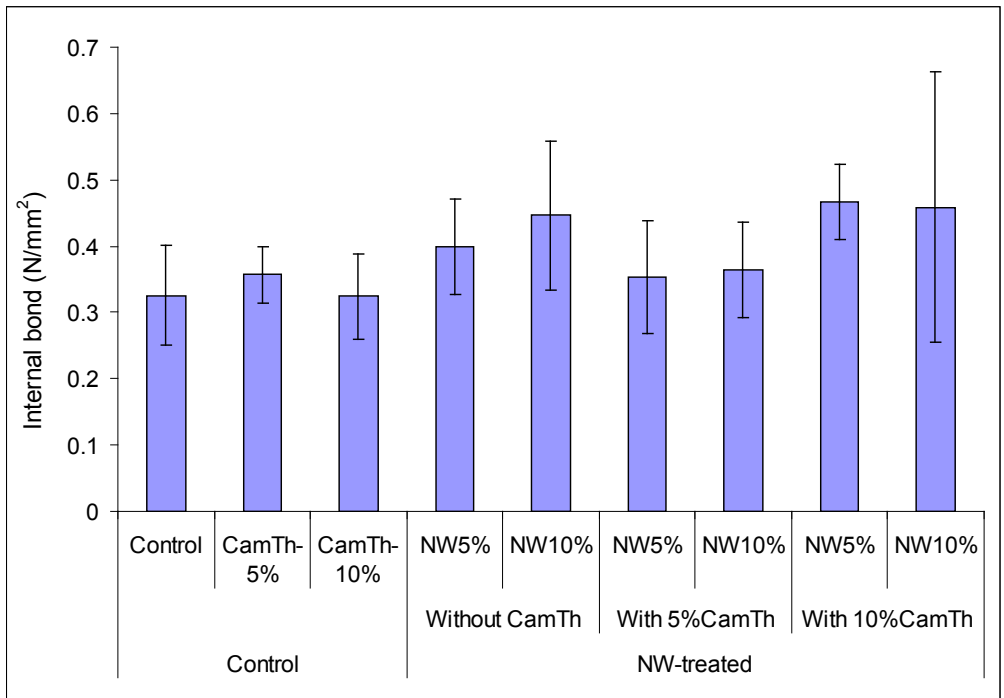

Figure 5. Effect of addition of wollastonite and/or camel thorn particles to wood based MCDF on internal bond strength (values represent averages of 10 replicates per variable. Error bars represent one standard deviation) (NW=nanowollastonite; $\mathrm{CamTh}=\mathrm{Camel}$ thorn). 


\section{Hardness}

There were slight variations in panel hardness among the various treatments, but addition of either camel thorn or NW had no significant effect on hardness $(\mathrm{P}<0,094)$ (Figure 6). Hardness can be affected by a variety of factors, but the most important would be the pressing conditions employed. Rapid press closure is likely to produce panels with higher surface densities that would have higher hardness values but all panels were produced using the same pressing conditions. The results suggest that hardness was only slightly affected by either NW or camel thorn.

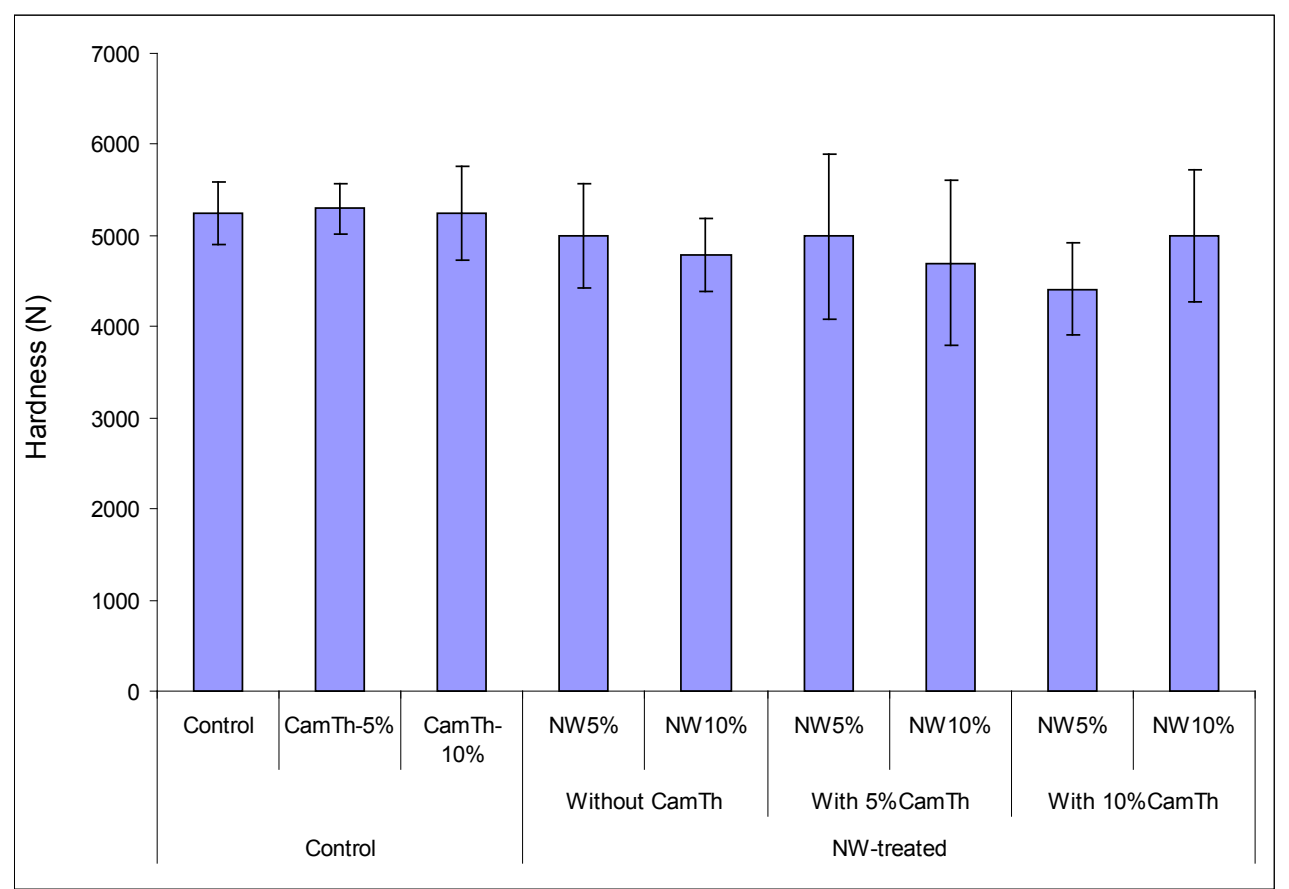

Figure 6. Effect of addition of wollastonite and/or camel thorn particles to wood based MCDF on hardness (values represent averages of 10 replicates per variable. Error bars represent one standard deviation) (NW=nanowollastonite; $\mathrm{CamTh}=$ Camel thorn).

\section{Scanning Electron Microscopic (SEM) Examination}

SEM examination was only useful for assessing the distribution of NW in the panels. NW appeared to be evenly distributed within the panels, suggesting that it was easily blended in the resin during processing to uniformly transfer the heat through the MDF mat during hot pressing (Figure 7). 


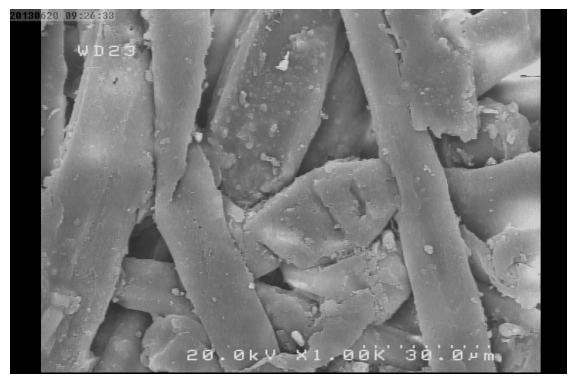

Figure 7. Scanning electronic micrograph showing locations of wollastonite particles in the interior of a MDF panel amended with 5\% NW.

\section{CONCLUSIONS}

Theaddition of wollastonitesignificantly improved the physical and mechanical properties inmediumdensity fiberboard made from wood fibers and camel-thorn chips. The addition of camel thorn chips did not negatively affect panel properties suggesting that this material might be useful substitute for wood fiber

\section{ACKNOWLEDGMENTS}

The senior authors acknowledge the support of the Shahid Rajaee Teacher Training University (SRTTU) under contract No. 22927 (Research project No. HT/2015-1007).

\section{REFERENCES}

Aitken, E. 2010. Analyses of the Effect of Silicon on Fusarium Wilt on Banana. Horticulture Australia, Sydney, NSW, Australia.

Akhtari, M.; Taghiyari, H.R.; Ghorbani-Kokandeh, M. 2013. Effect of some metal nanoparticles on the spectroscopy analysis of Paulownia wood exposed to white-rot fungus. Eur J Wood Prod 71(2): 283-285.

ASTM International. ASTM. 2012. Standard test methods for evaluating properties of woodbase fiber and particle panel materials. ASTM D1037-99. Volume 4.10., West Conshohocken, PA.

Drelish, J. 2013. Nanoparticles in a liquid: New state of liquid? J Nanomater Molecular Nanotechnol 2:1. doi: 10.4172/2324-8777.1000e105.

Huuskonen, M. S.; Jarvisalo, J.; Koskinen, H.; Nickels, J.; Rasanen, J.; Asp, S. 1983. Preliminary results from a cohort of workers exposed to wollastonite in a Finnish limestone quarry. Scandinavian Journal of Work, Environment, and Health 9(2): 169-175.

Institute of Standards and Industrial Research of Iran. 2000. Wood and wood-based panels: Specifications, ISIRI 9044. Tehran, Iran.

Joshi, S.; Drzal, L.; Mohanty, A.; Arora, S. 2004. Are natural fiber composites environmentally superior to glass fiber reinforced composites? Composites Part A: Applied Science and Manufacturing 35(3): 371-376.

Juliana, A.H.; Paridah, M.T.; Rhim, S.; Nor-Azowa, I.; Anwar, U.M.K. 2012. Properties of particleboard made from Kenaf (Hibiscus cannabinus L.) as function of particle geometry. Materials \& Design 34: 406-411.

Khojier, K.; Zolghadr, S.; Zare, N. 2012. Structural, electrical, and optical properties of 
molybdenum oxide thin films prepared by post-annealing of Mo thin films. International Journal of Bio-Inorganic Hybrid Nanomaterials 1(3): 199-207.

Li, D. 2012. Nanostructuring materials towards conventionally unachievable combination of desired properties. J Nanomater Mol Nanotechnol 1(1): dx.doi.org/10.4172/2324-8777.1000e102.

Maresi, G.; Oliveira-Longa, C.M.; Turchetti, T. 2013. Brown rot on nuts of Castanea sativa Mill: An emerging disease and its causal agent. iForest 6: 294-301.

Maxim, L. D.; McConnell, E. E. 2005. A review of the toxicology and epidemiology of wollastonite. Inhal Toxicol 17(9): 451-466.

Maxim, L. D.; Niebo, N.; McConnell, E. E. 2014a. Perlite toxicology and epidemiology - A review. Inhal Toxicol 26(5): 259-270.

Maxim, L. D.; Niebo, R.; Utell, M. J.; McConnell, E. E.; Segrave, A. M. 2014b. Wollastonite toxicity: An update. Inhal Toxicol 25(2): 95-112.

Nayeri, M.D.; Tahir, P.Md.; Harun, J.; Abdullah, L.C.; Suhaimi-Bakar, E.; Jawaid, M.; Namvar, F. 2013. Effects of temperature and time on the morphology, $\mathrm{pH}$, and buffering capacity of bast and core Kenaf fibers. BioResources 8(2): 1801-1812.

Ozdemir, F.; Tutus, A. 2013. The effects of some fire retardants on physical and mechanical properties of HDF panels covered with resin-impregnated paper. Lignocellulose 2(2): 329-337.

Rangavar, H. 2005. Instructions for wood-cement composite-boards using hardwoods. Wood Tech Equipment J 331: 236-241.

Saber, R.; Shakoori, Z.; Sarkar, S.; Tavoosidana, Gh.; Kharrazi, Sh.; Gill, P. 2013. Spectroscopic and microscopic analyses of rod-shaped gold nanoparticles interacting with singlestranded DNA oligonucleotides. IET Nanobiotechnol 7(2): 42-49.

Taghiyari, H. R.; Rangavar, H.; Nouri, P. 2013a. Fire-retarding properties of nano-wollastonite in MDF. Eur J Wood Prod 71(5): 573-581.

Taghiyari,H.R.; Mobini, K.; Sarvari-Samadi,Y.; Doosti,Z.; Karimi, F.;Asghari, M.; Jahangiri, A.; Nouri, P. 2013b. Effects of nano-wollastonite on thermal conductivity coefficient of medium-density fiberboard. J Nanomater Mol Nanotechnol 2(1) DOI: http://dx.doi.org/10.4172/2324-8777.1000106.

Taghiyari, H.R.; Karimi A.; Tahir, P.M.D. 2013c. Nano-wollastonite in particleboard: Physical and mechanical properties. BioResources 8(4): 5721-5732.

Taghiyari, H.R.; Bari, E.; Schmidt, O.; Tajick-Ghanbary, M.A.; Karimi, A.; Tahir, P.M.D. 2014a. Effects of nanowollastonite on biological resistance of particleboard made from wood chips and chicken-feather against Antrodia vaillantii. International Biodeterioration \& Biodegradation 90: 93-98.

Taghiyari, H.R.; Ghorbanali, M.; Tahir, P.M.D. 2014b. Effects of improvement in thermal conductivity coefficient by nano-wollastonite on physical and mechanical properties in mediumdensity fiberboard (MDF). BioResources 9(3): 4138-4149.

Xing, C.; Zhang, S.Y.; Deng, J.; Wang, S. 2007. Investigation of the effects of bark fiber as core material and its resin content on three-layer MDF performance by response furface methodology. Wood Science and Technology 41(7): 585-595.

Zini, E.; Scandola, M. 2011. Green composites: an overview. Polymer Composites DOI: 10.100. doi:10.1002/pc. 